\title{
REAPPRAISAL OF THE STRUCTURE OF ARTERIAL TUNICA ADVENTITIA AND ITS INVOLVEMENT IN ATHEROSCLEROSIS
}

\author{
Julius Ogeng'o PhD, MD; Beryl S. Ominde Bsc, MBchB; Kevin Ongeti Msc, Beda Olabu Msc; Moses Obimbo PhD, \\ Philip Mwachaka Msc
}

Correspondence to Julius Ogeng'o. Department Of Human Anatomy, University of Nairobi. P.O. BOX 30197 - 00100 Nairobi. Email: jogengo@uonbi.ac.ke Tel: 0720837592

\begin{abstract}
Tunica adventitia was previously considered an inert fibrous layer only involved in nutritional and physical support of the arterial wall. Recent studies reveal that it is an important dynamic layer actively involved in the regulation of vascular structure, function, response to injury and disease processes especially atherosclerosis. Many anatomical studies on arteries, however, still make only peripheral reference to it, without elucidating its detailed structure. Knowledge of the latter is important in understanding pathobiology and interventional approaches to atherosclerosis. This review, therefore, aims at consolidating contemporary literature on the structure and clinical significance of the arterial tunica adventitia. Google literature search was done using the key words tunica adventitia combined with: artery, aorta, cells, cell types, collagen, elastic fibres, vasa vasora, lymphatics, nerves, atherosclerosis. There is overwhelming evidence that the tunica adventitia comprises multiple types of collagen and elastic fibres arranged in various directions, a wide variety of cells including fibroblasts, smooth muscle, pericytes, myofibroblasts, leukocytes, mononuclear phagocytic, defence, mesenchymal stem and mast cells; vasa vasora including microvasculature, lymphatics and neural elements. The exact cellular, fibre composition and orientation vary between various arteries and regions of the same vessel. Its components are involved in the initiation, progression and complications of atherosclerosis. In conclusion, the tunica adventitia is an active dynamic layer which, besides mechanical and nutritive functions; has metabolic, regulatory and defence roles that are critical in arterial homeostasis and atherosclerosis. Vascular studies should always include detailed analysis of the biology of the tunica adventitia.
\end{abstract}

Key words: Tunica adventitia, cells, fibres, vessels, nerves, atherosclerosis

\section{INTRODUCTION}

Tunica adventitia (TA) of arteries has previously been regarded as a passive compartment involved in only physical and nutritive support of the vessel wall. Recent data, however, reveal that it is actively involved in regulating the structure, function and disease processes of the vessel wall (Stenmark et al., 2012, 2013; Tang et al., 2013). Its removal leads to degeneration of the entire tunica media and disruption of tunica intima (Fugundes et al., 2012). Accordingly, there is renewed interest in its biology with many studies focusing on its role in atherosclerosis (Skilton et al., 2009, 2011, 2012;
Simionescu and Sima, 2012; Campbell et al., 2012). We recently described features of atherosclerosis in the tunica adventitia of coronary and carotid arteries (Ogeng'o et al., 2014) and further reported morphological evidence that it is an active compartment (Ogeng'o et al., 2015). In spite of this, most studies on structure of arteries focus more on tunica intima and media with only peripheral reference to the tunica adventitia (Nowrozani, 2011; Popescu et al., 2013). Some of its components are under emphasized. Data on the structural components of tunica adventitia in

Submitted $7^{\text {th }}$ October 2016, revised on $7^{\text {th }}$ November 2016. Published online $12^{\text {th }}$ December 2016 . To cite Ogeng'o J, Ominde B, Ongeti K, Olabu B, Obimbo M, Mwachaka P. 2017. Reappraisal of the structure of the arterial tunica adventitia and its involvement in atherosclerosis. Anatomy Journal of Africa. 6: $824-833$. 
normal arteries are important in enhancing understanding of their physicomechanical properties, functions, disease processes like atherosclerosis, aneurysms and potential interventional strategies. Indeed, the tunica adventitia is currently an area of focus for therapeutic intervention in atherosclerosis (Tian et al., 2013; Kharlamov et al., 2013). This review, therefore, aims at consolidating available contemporary literature on various components of the tunica adventitia, and their involvement in atherosclerosis

\section{LITERATURE REVIEW}

Relevant publications over the last 25 years in anatomy, pathology, cardiology, biology, cardiovascular surgery and therapeutics were retrieved from Google search using the key words tunica adventitia, combined with artery, aorta, structure, disease, atherosclerosis, organization, cells, cell types, collagen, elastic, fibres, vascularity, vessels, tissues, vasa vasora, lymphatics nerves and innervation in various combinations. A few older classical reports were included. Only the articles which were explicit on structural components were included in the review.

The TA is actively involved in regulating structure, function and disease processes of the vessel wall (Stenmark et al., 2012, 2013; Tang et al., 2013). It contains connective tissue fibres, heterogeneous population of cells, vasa vasora, lymphatic networks and nervous tissue (Ponticos et al., 2004; Kielty et al., 2007; Mulligan - Kehoe and Simons, 2014). The details of the organization of each of these different elements and their involvement in atherosclerosis are outlined below.

\section{Fibre Composition}

The TA of large blood vessels is typically a fibroelastic jacket (Viegas et al., 2001; Orsi et al., 2004; Mello et al., 2004; Nowrozani, 2011). Although conventionally known to comprise mainly collagen type I, 17 different collagen types have been identified in the mouse aorta, for example, with collagens I, III, IV, V, VI, VII, VIII having the highest expression levels (Keller et al., 1996; Plenz et al., 2003; McLean et al., 2005; Megens et al., 2007; Wagensil and Mecham, 2009; Stankovic et al., 2015). Collagens I, III, and V are fibril-forming collagens, with types I and III being mainly responsible for imparting strength to the vessel wall. The distribution of collagen types I and III varies depending on the specific region of the vascular tree. In the ascending aorta, collagens I and III colocalize. These collagens are dispersed in all directions (Scacel and Bursa, 2013), confer structural stability, influence cellular differentiation, adheshion, migration, proliferation and apoptosis (Pontico and Smith, 2014; Stankovic et al., 2015).

The elastic fibres of the TA comprise fibrous forms containing tubular elastin, cord like shapes (Ushiki and Murakumo, 1991) and lamellar forms of variable thickness with transverse, oblique and longitudinal arrangements forming a mosaic (Hass et al., 1990; Orsi et al., 2004). Apart from mature elastic fibres which appear randomly dispersed (Kielty et al., 2007), the TA also contains oxytalan and elaunin fibres (Baba et al., 1988; Ogeng'o, 2008). The quantity of elastic tissue varies between arteries and also between arterial segments (Csibi et al., 2015).

\section{Cellular Composition}

The TA has been reported to comprise only fibroblasts and macrophages (Tonar et al., 2010; Nowrozani et al., 2011). Further, the population of cells in the TA was initially thought to be static and passive with only structurally supportive and protective roles. There is overwhelming data, however, to show that TA also contains resident populations of macrophages, $T$ and $B$ lymphocytes, pericytes, myofibroblasts, mast, endothelial, smooth muscle; mesenchymal, dendritic cells (Galkina et al., 2006; Tieu et al., 2009; Zhou et al., 2010; Swedenborg et al., 2011) and adipocytes (Tang et al., 2013). Further, it harbours stem/progenitor cells (Campagnolo et al., 2010; Majesky et al., 2011; 
Simionescu and Sima, 2012; Stenmark et al., 2012, 2013; Ogeng'o et al., 2015). Some of these cells may represent an important source of pericytes for angiogenesis during remodeling of the artery in physiological and pathological processes (Torsney et al., 2005; Corselli et al., 2012) and also provide a convenient supply of mural cells for vascular bioengineering applications (Howson et al., 2005).

There are two types of perivascular cells, namely pericytes and adventitial cells. These cells have been implicated in constituting multipotent progenitor cells similar to mesenchymal stem cells (Corselli et al., 2012; Stenmark et al., 2013) involved in routine remodeling and response to injury. Some of them may also be involved in immune surveillance. These numerous cell types in the TA contribute to active cross talk between $\mathrm{TA}$, tunica media and intima of the vascular wall in the maintenance of its structure, function and response to injury (Campbell et al., 2012).

\section{Vasa Vasora}

Vasa vasora (VV) are the vessels of the vascular wall. The tunica adventitia contains the external vasa, that is those derived from external arteries. There are three types of $\mathrm{V} V$, namely arterial vasa vasora (AVV), venous vasa vasora (VVV) and lymphatic vasa vasora (LVV) [Sacchi et al., 1990; Ritman and Lerman, 2007; Mulligan - Kehoe and Simons, 2014]. The distribution and density of adventitial VV differ between vascular beds and different segments (Galili et al., 2004). For example, the density of VV is higher in coronary than in renal and femoral arteries (Hildebrandt et al., 2008). With regard to regional variation, the density of $\mathrm{W}$ is higher in proximal than in distal segments (Ritman and Lerman, 2007; Tonar et al., 2016; Sano et a.I., 2016). The intra and intervessel heterogeneity in V anatomy is a phenotypic variability that may determine a differential local response to systemic risk factors (Galili et al., 2004).

Arterial Vasa Vasora: The AVV consist of a muscular main artery from which smaller arteries branch dichotomously and interconnect to form a plexus. They function like end arteries and supply the TA and TM (Ritman and Lerman,
2007; Fugundes et al., 2012; Mulligan - Kehoe and Simons, 2014).

Venous Vasa Vasora: These run parallel to the AVV and drain the arterial wall into the largest branches of feeder veins or companion veins (Mulligan - Kehoe and Simons, 2014). Tunica adventitia also harbours a dynamic microvasculature comprising a dense network of arterioles and capillaries (Majesky et al., 2011; Simionescu and Sima, 2012; Ogeng'o et al., 2015).

Lymphatic Vasa Vasora: The TA contains a rich irregular plexus of various sizes of lymphatic vessels (Sacchi et al., 1990; Drozdz et al., 2008; 2012). They form a network consisting of large and sparsely distributed vessels with capillary structure and occupy a more external position than blood capillaries. They are involved in reverse transport of cholesterol, and other lipid from the arterial wall and immune cells to the regional lymph nodes and regulate disease processes of arterial wall especially inflammatory and immune responses in atherosclerosis ( $\mathrm{Xu}$ et al., 2009; Kut Kut et al., 2015; Milasan et al., 2015).

\section{Nervi Vasora}

Nervi vasora (NV) are the nerves that supply the vessel wall. In the TA, NV take the form of nerve terminals, fibre plexi, varicosities and ganglia which vary depending on the size and location of the artery (Appenzeller, 1964; Fisher, 1965). Adrenergic and cholinergic axons often contain many granular and agrannular synaptic vesicles and are free of Schwann cell sheath (Iwayama et al., 1970). The plexi comprise interlacing nerve fibres of postganghonic sympathetic nerves, Schwan cells and periodic axonal swellings which are sites of synthesis, storage, release and uptake of neurotransmitters (Bevan and Su, 1973). Unmyelinated adrenergic nerve fibres accompany small penetrating arteries and travel within the adventitia for long distances before reaching a branching site. The nerve fibres are embedded in Schwann cell cytoplasm. Each nerve fibre contains $10-40$ axons associated with the basement membrane, presumably derived from Schwann cells. Axons 
display large central mitochondria and abundant neurofilaments, microtubules and dense core vesicles typical of those containing catecholammes (Briggs et al., 1985). Sensory nerve terminals characterized by abundance of mitochondria are found in the deeper parts (Kimani and Mungai, 1983). Functionally, the nervous elements in the TA have been classified into sympathetic, parasympathetic and sensory (Bleys et al., 1996). Indeed, cholinergic (Mitchell, 2004) and adrenergic terminals (Reddy et al., 2011) have been described in TA of various arteries.

\section{Regional and inter arterial differences}

Regional differences in the size and composition of TA have been described in several arteries. In the goat aorta, for example, there is a craniocaudal increase in thickness and elastic fibre content such that in the ascending aorta, aortic arch and proximal descending aorta, the tunica adventitia is thin, and consists predominantly of collagen fibres, with a few scattered elastic fibres running in different directions. In the abdominal region, on the other hand it is much more prominent, compact and contains more elastic fibres than in the thoracic part (Ogeng'o et al., 2010). In lamb external iliac arteries, the adventitia is very thick, occupying about $45 \%$ of arterial thickness and with numerous compact elastic fibres. In the left common carotid artery of the same animal, on the other hand, the TA displays a loose architecture with only a few elastic fibres (Csibi et al., 2015).

\section{Involvement in atherosclerosis}

Tunica adventitia is actively involved in the initiation, progression and complications of atherosclerosis (Torsney et al., 2005; Campbell et al., 2012) through the "outside -in" mechanism (Maiellaro and Taylor, 2007; Langreinrich et al., 2007; Mulligan - Kehoe, 2010).

The main structural events involved are increased adventitial thickness, cellular invasion and proliferation, vasa vasora neovascularization; lymphatic proliferation and autonomic dysregulation.

\section{Increased Adventitial thickness}

Adventitial thickness increases in response to atherogenic stimuli and during atherosclerosis (Rioufol et al., 2006; Falk et al., 2009; Skilton et al., 2009). Such adventitial thickening is consistent with the outside-in mechanism of atherogenesis in which the inflammation is initiated in the tunica adventitia as the first responder early in the disease process and progresses inwards towards the intima (Maiellaro and Taylor, 2007; Stenmark et al., 2013; Wang et al., 2013). Indeed, adventitial thickness may increase before intimal hyperplasia (Ogeng'o et al., 2014). The increase in thickness of TA correlates with cardiovascular risk factor profile and occurs in tandem with increase in IMT (Kazmierski et al., 2009; Skilton et al., 2011, 2012). Measurements that capture the intima, media and adventitia of the arterial wall, have been found to be most closely correlated with the number of cardiovascular risk factors (Falk et al., 2009; Skilton et al., 2011).

\section{Cellular invasion and proliferation}

Fibroblasts are activated by atherogenic stimuli to replicate, differentiate into myofibroblasts and produce chemokines and cytokines that trigger influx of inflammatory cells including monocytes, macrophages, B and $\mathrm{T}-$ lymphocytes (Wick et al., 1997; Caspers et al., 1997; Bush et al., 2000; Gradus - Pizlo et al., 2003; Stenmark et al., 2012). The inflammatory cells may directly stimulate medial SMC migration and proliferation, as well as disrupt ongoing adventitial niche signaling to enable the differentiation of resident progenitor cells towards a SMC - like fate. The resident and migrating cells deposit collagen and matrix components, respond to and upregulate inflammatory chemokines and/or antigens and regulate the local redox state of the adventitia. $\mathrm{B}$ and $\mathrm{T}$ lymphocytes generate local humoral immune responses against local antigen presentation by foam cells and other antigen presenting cells. Indeed, these cells in the adventitia contribute to intimal hyperplasia synergistically with SMC and through cross talk 
with the tunica media and intima (Tang et al., 2013).

\section{Vasa vasora neovascularization}

Vasa Vasora neovascularisation is one of the earliest events of atherosclerosis, preceeding increase in IMT and development of plaque (Herrmann et al., 2001; Fleiner et al., 2004; Moreno et al., 2006). The channels serve as conduits for delivery of a wide range of inflammatory cells into the plaque, causing chronic vascular inflammation and rapid expansion of the atherosclerotic plaques (Kolodgie et al., 2003; Sluimer et al., 2009). They also serve as the sources of vascular stem cells (VSCs) including multipotent pericytes and endothelial progenitor cells. These VSCS differentiate into several cells - VSMCs, endothelial cells and fibroblasts and contribute to atherosclerotic modeling (Kawabe and Hasebe, 2014). With progression of atherosclerosis and increasing plaque thickness, ischemia of the vessel wall induces release of angiogenic growth factors and development of intimal neovascularization (Koldgie et al., 2003; Staub et al., 2010; Gossl et al., 2010). These new fragile microvessels allow local extravasation of blood (Sluimer et al., 2008). This intraplaque hemorrhage expands the necrotic core and induces rapid plaque progression and subsequent atherothrombosis (Kolodgie et al., 2003). Adventitial LVV also proliferate in response to atherogenic risk factors (Xu et al., 2009) and increase with progression of atherosclerosis (Drodz et al., 2008; Drodz et al., 2012; Milasan et al., 2015; Kut Kut et al., 2015).

\section{Involvement of nerves}

Sympathetic neurotransmitters may play a role in the development of atherosclerosis ( $\mathrm{Li}$ et al., 2003; Sobey, 2003). Further, autonomic dysregulation induces adventitial dysfunction which is a critical event in atherosclerosis (Yun et al., 2005). Hyperactivation of sympathetic neural activity has pro - atherogenic effects on vascular function by increasing vascular vasoconstriction, accumulation of modified lipoprotein in the vascular wall, induction of endothelial dysfunction and stimulation of oxidative stress and vascular remodeling (Christiakov et al., 2015). Indeed, Sympathectomy ameliorates progression of atherosclerosis (Lichtor et al., 1987).

In conclusion, the tunica adventitia is a heterogeneous, dynamic and active vascular compartment with microvasculature, lymphatic vessels and multiple populations of cells and nerves. These components enable it to maintain structural and functional integrity and are involved in the initiation, progression and complications of atherosclerosis. It is actively involved in priming the tunica media and intima, is sensitive to injury and constitutes a potential target for therapeutic intervention. Tunica adventitia should therefore be more robustly studied and prioritized in evaluation of vulnerable arteries for atherosclerosis and therapeutic interventions.

\section{ACKNOWLEDGEMENT}

We are grateful to James macharia, Jackson Gachoka, Christopher Kamwaro, Esther Mburu for technical support in our work and Antonina Odock_ Opiko for typing the manuscript.

\section{REFERENCES}

1. Appenzeller O. 1964. Electron microscopic study of the innervation of the auricular artery in the rat. J Anat Lond; 98: $87-91$.

2. Baba T, Takagi M, Kagami A, Hishikawa H, Hosokawa Y. 1988. Ultrastuctural and cytochemical properties of elastin - associated microfibrils and their relation to fibronectin. Histochem J; 20: $688-696$.

3. Bevan JA, Su C. 1973. Sympathetic mechanisms of blood vessels: nerve and muscle relationships. Ann Rev Pharmacol; 13: 269 - 285. 
4. Bleys RLAW, Cowen T, Groen GJ, Hillen B, Ibrahim NBN. 1996. Perivascular nerves of human basal cerebral arteries: I. Topographical Distribution. J Cerebral Blool Flow Metab; 16: 1034 1047.

5. Briggs L, Garcia JH, Conger KA, Pinto De Moraes H, Geer JC, et al. 1985. Innervation of Brain intraparechymal vessels in sub human primates: Ultrastructural observations. Stroke; 16: 297 301.

6. Bush E, Maeda N, Kuziel WA, Dawson TC, Wilcox JN, DeLeon H, et al. 2000. CC chemokine receptor 2 is required for macrophage infiltration and vascular hypertrophy in angiotensin IIinduced hypertension. Hypertension; 36:360-633.

7. Campagnolo P, Cesselli D, Al Haj Zen A, Beltrami AP, Krankel N, Katare R, et al. 2010. Human adult vena saphena contain perivascular progenitor cells endowed with clonogenic and proangiogenic potential. Circulation; 121:1735-1745.

8. Campbell KA, Lipinski MJ, Doran AC, Skaflen MD, Fuster V, McNamara CA. 2012. Lymphocytes and adventitial immune response in atherosclerosis. Circ Res; 110: $889-890$.

9. Caspers IVQ, Alexander RW, Lou P, DeLeon H, Wilcox JN, Ishizaka N, et al. 1997. Monocyte chemoattractant protein-1 expression in aortic tissues of hypertensive rats. Hypertension; 30:1397-1402.

10. Christiakov DA, Ashwell KW, Orekhov AN, Bobryshev YN. 2015. Innervation of the arterial wall and its modification in atherosclerosis. Auton Neurosci; 193: $7-11$.

11. Corselli M, Chen CW, Sun B, Yap S, Rubin JP, Peault B. 2012. The Tunica adventitia of Human Arteries and veins as a source of mesenchymal stem cells. Stem cell and Development; 21: 1299 $-1308$.

12. Csibi D, Ruxanda F, Rus V, Martons C, Ratiu C, Mielaus V. 2015. Assesment of elastic component of tunica adventitia of some arteries in lamb. Bull UASVM Vet Med; 72: 270 - 276.

13. Drozdz K, Janczak D, Dziegiel P, Podhorska M, Patrzalek D, Ziolkowski $P$, et al. 2008. Adventitial lymphatics of internal carotid artery in healthy and atherosclerotic vessels. Folia Histochemica et Cytobiologica; 46: 433 - 436.

14. Drozdz K, Janczak D, Dziegiel P, Podhorska M, Piotrowska A, Patrzalek D, et al 2012. Adventitial lymphatics and atherosclerosis. Lymphology; 45: $26-33$.

15. Falk E, Thim T, Kristensen IB. 2009. Atherosclerotic plaque, Adventitia, perivascular Fat and Carotid imaging. J Am Coll Cardiol Imag; 2 : 183 - 186.

16. Fisher AWF. 1965. The intrinsic innervation of pulmonary vessels. Acta Anatomica; 60: $481-496$.

17. Fleiner M, Kummer M, Mirlacher M, Sauter G, Cathomas G, Krapf R et al. 2004. Arterial neovascularization and inflammation in vulnerable patients: early and late signs of symptomatic atherosclerosis. Circulation; 110:2843-50.

18. Fugundes A, Pereira AH, Correa K, de Oliveira MT, Rodriguez R. 2012. Effects of removal of the adventitia of the descending aorta and structural alterations in the tunica media in pigs. Rev Col Bras Circ; 39: 133 -137.

19. Galili O, Herrmann J, Woodrum J, Sattler KJ, Lerman LO, Lerman A. 2004. Adventitial vasa vasorum heterogeneity among different vascular beds. J Vasc Surg; 40: 529 - 535.

20. Galkina E, Kadl A, Sanders J, Varughese D, Sarembock IJ, Ley K. 2006. Lymphocyte recruitment into the aortic wall before and during atherosclerosis is partially $L-$ selectin dependent. $J$ Exp Med; 203: $1273-1282$.

21. GossI M, Versari D, Hildebrandt HA, Bajanowski T, Sangiorgi G, Erbel R, et al. 2010. Segmental heterogeneity of vasa vasorum neovascularization in human coronary atherosclerosis. $\mathrm{J} \mathrm{Am} \mathrm{Coll}$ Cardiol Img; 3:32-40. 
22. Gradus - Pizlo I, Bigelow B, Mahomed Y, Sawada SG, Rieger K, Feigenbaum H. 2003. Left anterior descending coronary artery wall thickness measured by high frequency transthoracic and epicardial echocardiography includes adventitia. Am J Cardiol, 91: 27 - 32.

23. Hass KS, Phillips SJ, Camerota AJ, White JV. 1990. The architecture of adventitial elastin in the canine infrarenal aorta. Anatomical Record; 230: 86-96.

24. Herrmann J, Lerman LO, Rodriguez-Porcel M, Holmes Dr Jr, Richardson DM, Ritman EL, et al. 2001. Coronary vasa vasorum neovascularization precedes epicardial endothelial dysfunction in experimental hypercholesterolemia. Cardiovasc Res; 51:762-6.

25. Hildebrandt HA, Gossl M, Mannheim D, Versari D, Herrman J, Spendlove D et al. 2008. Differential distribution of vasa vasorum in different vascular beds in humans. Atherosclerosis; 199: $47-54$.

26. Howson KM, Aplin AC, Getati M, Allesandri G, Parati EA, Nicosia RF. 2005. The postnatal rat aorta contains pericyte progenitor cells that form spheroidal colonies in suspension culture. $A m \mathrm{~J}$ Physiol: Cell physiol; 289: C $1396-1407$.

27. Iwayama T, Furness JB, Burnstock G. 1970. Dual adrenergic and cholinergic innervation of the cerebral arteries: An ultrastructural study. Circ Res; XXVI: $635-646$.

28. Kawabe J, Hasebe N. 2014. Role of the vasa vasorum and vascular resident stem cells in atherosclerosis. Biomed Res Int; 701571. Doi: 10.1155/2014/701571.

29. Kazmierski R, Watala C, Podsiadly E, Dorzewrska J, Kozubski W. 2009. Association of atherosclerotic risk factors with carotid adventitial thickness assessed by ultrasonography. $\mathrm{J}$ Clin Ultrasound, 37: $333-341$.

30. Keller BB, MacLennan MJ, Tinney JP, Yoshigi M. 1996. In vivo assessment of embryonic cardiovascular dimensions and function in day-10.5 to -14.5 mouse embryos. Circ Res; 79:247255.

31. Kharlamov AN, Duckers HJ, Van Beuskon HMM, Smits PC, Perin EC, Serruys PW. 2013. Do we have a future with transcatheter adventitial delivery of stem cells? Int J Cardiol; 165: 217 - 221.

32. Kielty CM, Stephen S, Sheratt MJ, Williamson M, Shuttleworth CA. 2007. Applying elastic fibres biology in vascular tissue engineering. Philos Trans Soc Lond B Biol Sci; 362: 1293 - 1312.

33. Kimani JK, Mungai JM 1983. Observations on the structure and innervation of the presumptive carotid sinus area in the giraffe (Giraffa camelopardalis). Acta Anat; 115: 117 - 133.

34. Kolodgie FD, Gold HK, Burke AP, Powler DR, Kruth HS, Weber DK et al. 2003. Intraplaque hemorrhage and progression of coronary atheroma. N Engl J Med; 349:2316-25.

35. KutKut I, Meens MJ, Mckee TA, Bochaton - Piallat ML, Kwak BR. 2015. Lymphatic vessels: an emerging factor in atherosclerotic plaque development. Eur J Clin Invest; 45: 100 - 108.

36. Langheinrich AC, Kampschulte M, Buch T, Bohle RM. 2007. Vasa vasorum and atherosclerosis Quid novi? Thromb Haemost; 97: 873 - 879.

37. Li L, Lee EW, Ji H, Zukowska Z. 2003. Neuropeptide Y- induced acceleration of post angiography occlusion of rat carotid artery. Arterioscler Thromb Vasc Biol, 23: $1204-1210$.

38. Lichtor T, Davis HR, Johns L, Vesselinovitch D, Wissler RW, Mullan S. 1987. The sympathetic nervous system and atherosclerosis. J Neurosurg; 67: $906-914$.

39. Maiellaro K, Taylor WR. 2007. The role of the adventitia in vascular inflammation. Cardiovasc Dis; 75:640 - 648.

40. Majesky MW, Dong XR, Hoglund VJ, Mahoney WM, Daum G. 2011. The adventitia: a dynamic interface containing resident progenitor cells. Arterioscler Thromb Vasc Biol; 31: 1530 - 1539.

41. McLean SE, Mecham BH, Kelleher CM, Mariani TJ, Mecham RP. 2005. Extracellular matrix gene expression in developing mouse aorta. In: Miner $\mathrm{JH}$, editor. Extracellular Matrices and Development. Elsevier; New York: pp. 82-128. 
42. Megens RJA, Egbrink MGA, Cleutjens JPM, Kuijpers MJE, Schiffers PHM, Merkx M, et al. 2007. Imaging collagen in intact viable healthy and atherosclerotic arteries using fluorescently labeled CAN 35 and two - photon laser scanning microscopy. Mol Imaging; 4: $247-260$.

43. Mello JM, Orsi AM, Padovani CM, Matheus SMM, Eleuterio ML. 2004. Structure of the aortic wall in the Guinea Pig and Rat. Braz J Morphol Sci; 21: 35 - 38.

44. Milasan A, Ledoux J, Martel C. 2015. Lymphatic network in atherosclerosis: the underestimated path. Future Science OA; 1: 4. Doi 10.4155/fso15.61.

45. Mitchell JA. 2004. An investigation of sympathetic innervation of the vertebral artery in primates: is there a neurogenic substrate for vasoconstriction? Eur J Histochem; 48; $309-316$.

46. Moreno PR, Purushothaman KR, Sirol M, Levy AP, Fuster V. 2006. Neovascularization in human atherosclerosis. Circulation; 113: 2245 - 2252.

47. Mulligan - Kehoe MJ. 2010. The vasa vasorum in diseased and non diseased arteries. $A m$ J Physiol: Heart Circ Physiol; 298: H295 - H305.

48. Mulligan - Kehoe MJ, Simons M. 2014. Vasa vasora in normal and diseased arteries. Circulation; 129: $2557-2566$.

49. Nowrozani FR. 2011. Comparison of abdominal aorta and renal artery in the neonatal male dog. J Animal Vet Adv; 10: 2278 - 2281.

50. Ogeng'o JA, Malek AK, Kiama SG. 2010. Regional differences in aorta of goat (capra hircus). Folia Morphol (warz); 69: 253 - 257.

51. Ogeng'o JA, Ongeti K, Obimbo M, Olabu B, Mwachaka P. 2014. Features of atherosclerosis in the tunica adventitia of coronary and carotid arteries in a black Kenyan population. Anat Res Intl, 2014: Article ID 456741.

52. Ogeng'o JA, Maseghe P, Ongeti K, Obimbo M, Olabu B. 2015. Tunica adventitia of the aorta in an active vascular compartment. Anat J Afr; 4: 617 - 623.

53. Ogeng'o JA. 2008. Structure and adrenergic innervation of the aorta in the goat (capra hircus). PhD thesis, University of Nairobi; pp $80-83$.

54. Orsi AM, Stefanini MA, Crocci AJ, Simoes K, Ribeiro AACM. 2004. Some segmental features on the structure of the aortic wall of the dog. Anat Histol Embryol, 31: 131-134.

55. Plenz G, Deng AMC, Robeneck H, Volker W. 2003. Vascular collagens: spotlight on the role of type VIII collagen in atherogenesis. Atherosclerosis; 166: $1-11$.

56. Ponticos M, Partridge T, Black CM, Abraham DJ, Bou - Gharius G. 2004. Regulation of collagen type 1 in vascular smooth muscle cells by competition between NKx 2.5 and EF1/ZEB1. Mol Cell Biol; 24: $6151-6161$.

57. Ponticos M, Smith BD. 2014. Extracellular matrix synthesis in vascular disease: hypertension and atherosclerosis. J Biomed Res; 28: 25 - 39.

58. Popescu MR, Zugun FE, Cojocaru E, Toran L, Folescu R, Zamfir CL. 2013. Morphometric study of aortic wall parameters evolution in newborn and child. Rom J Morphol Embryol; 54:399 - 404.

59. Reddy S, Kumar P, Prasad K. 2011. Histomorphometric and sympathetic innervation of the human superficial temporal artery. Ind J Plastic Surg; 44: $127-133$.

60. Rioufol G, Elbaz M, Dubreuil O, Tabib A, Finet G. 2006. Adventitia measurement in coronary artery: an in vivo intravascular ultrasound study. Heart; 92: $985-986$.

61. Ritman E, Lerman A. 2007. The dynamic vasa vasora. Cardiovasc Res; 75: $649-658$.

62. Sacchi G, Weber E, Comparini L. 1990. Histological framework of lymphatic vasa vasorum of major arteries. An experimental Study. Lymphology; 23: 135 - 139.

63. Sano M, Unno N, Sasaki T, Baba S, Sugisawa R, Tanaka H. 2016. Vasa vasorum and lymphatic vasa vasorum in the aortic adventitia - Implications for the prevalence of aortic diseases. Atherosclerosis; 247: $127-134$. 
64. Scacel P, Bursa J. 2013. Numerical implementation of constitutive model for arterial layers with distributed collagen fibre orientations. Comp Methods Biomech Biomed Eng, 18: doi:10.1080/10255842.2013.847928.

65. Simionescu M, Sima AV. 2012. Morphology of atherosclerotic lesions. IN - Inflamation and atherosclerosis. G Wick and C. Grundtman, Eds, Springer, Vienna, Austria, pp. $19-37$.

66. Skilton MR, Serusclat A, Sethu AH, Brun S, Bernard S, Baikau B et al. 2009. Noninvasive measurement of carotid extra-media thickness: associations with cardiovascular risk factors and intima-media thickness. JACC Cardiovasc Imaging; 2:176-82.

67. Skilton MR, Boussel L, Benard S, Douek PC, Moulin P, Serusclat A. 2011. Carotid intima - media and adventitial thickening: comparison of new and established ultrasound and magnetic resonance imaging techniques. Atherosclerosis; 215: $405-410$.

68. Skilton MR, Suliivan TR, Ayer JG, Harmer JA, Toelle BG, Webb et al. 2012. Carotid extramedial thickness in childhood: early life effects on arterial adventitia. Atherosclerosis; 222: $478-482$.

69. Sluimer JC, Gasc JM, van Wanroij JL, Kisters N, Groeneweg M, Sollewijn G et al. 2008. Hypoxia, hypoxia-inducible transcription factor, and macrophages in human atherosclerotic plaques are correlated with intraplaque angiogenesis. J Am Coll Cardiol, 51: 1258-65.

70. Sluimer JC, Kolodgie FD, Bijnens AP. 2009. Thin - walled microvessels in human coronary atherosclerotic plaques show incomplete endothelial junctions. Relevance of compromised structural integrity for intraplaque microvascular leakage. J Am Coll Cardiol; 53: 1517 - 1527.

71. Sobey CG. 2003. Neurogenic atherosclerosis mediated by neuropeptide Y. Arterioscler Thromb Vasc Biol, 23: 1137 - 1139.

72. Stankovic ST, Sazdanovic M, Jovicic N, Milovanovic J, Lackovic M. 2015. Modern view of the structure of the vascular extracellular matrix. Med Cas (Krag) Med J (Krag); 49: 13 - 19.

73. Staub D, Schinkel AFL, Coll B, Coli S, Van Der Steen AFW, Reed JD et al. 2010. Contrast enhanced ultrasound imaging of the vasa vasorum. J Am Coll Cardiol Img; 3: 761 - 771.

74. Stenmark KR, Frid MG, Yeager M, Li M, Riddle S, McKinsey T, et al. 2012. Targeting the adventitial microenviroment in pulmonary hypertension: a potential approach to therapy that considers epigenetic change. Pulm Circ; 2: 3 - 14.

75. Stenmark K, Yeager M, El Kasmi KC, Nozik - Grayck E, Gerasimovskaya EV, Li M. 2013. The adventitia: essential regulator of vascular structure and function. Ann Rev Pysiol, 75: 23 - 47.

76. Swedenborg J, Maryanpaa MI, Kovanen PT. 2011. Mast cells: important players in the orchestrated pathogenesis of abdominal aortic aneurysms. Arterioscler Thromb Vasc Biol; 31:734-740.

77. Tang W, Liu Z, Si Y. 2013. Tunica arterial adventitia: a new exploration in intimal hyperplasia. J Vasc Med Surg, 1: 108.doi:10.4172/2329 - 6925.1000108.

78. Tian J, Hu S, Sun Y, Yu H, Han X, Cheng W, et al. 2013. Vasa vasorum and plaque progression, and responses to atorvastatin in a rabbit model of atherosclerosis: contrast enhanced ultrasound imaging and intravascular ultrasound study. Heart; 99: 48 - 54.

79. Tieu BC, Lee C, Sun H, LeJeune W, Recinos A, 3rd, Ju X, et al. 2009. An adventitial IL6/MCP1 amplification loop accelerates macrophage-mediated vascular inflammation leading to aortic dissection in mice. J Clin Invest;119:3637-3651.

80. Tonar Z, Witter K, Krizkova V, Eberlova L, Kirova J, Molacek J. 2010. Stereological tools for quantitative microscopy of the aortic wall with focus on the abdominal aortic aneurysm. Microscopy: Science, Technology, Applications and education. A Mendez-vilas and J Diaz (Eds);926 -935.

81. Tonar Z, Tomasek P, Loaskot P, Jamacek J, Kralickova M, Witter K. 2016. Vasa Vasorum in the tunica media and tunica adventitia of the porcine aorta. Ann Anat; 205: 22 - 36. 
82. Torsney E, Hu Y, Xu Q. 2005. Adventitial progenitor cells contribute to atherosclerosis. Trend Cardiovasc Med; 15: $64-68$.

83. Ushiki T, Murakumo M. 1991. Scanning electron microscopic studies of tissue elastin components exposed by / KOH - collagenase or simple $\mathrm{KOH}$ digestion method. Arch Histol Cytol; 54: 427 436.

84. Viegas KA, Orsi AM, Matheus SMM, Francia-Farje LAD, Orsi DC, Mello JM. 2001. Características estructurales de la aorta del conejo (Oryctolagus cuniculus). Review of Clinical Anatomy; 19: 131 $-137$.

85. Wagensil JE, Mecham RP. 2009. Vascular extracellular matrix and arterial mechanics. Physiol Rev; 89: 957 - 989.

86. Wang JL, Ma SQ, Li L, Liu GQ, Hu WC, Ma R. 2013. Correlation of inflammatory cells in adventitia and formation and extending of atherosclerotic lesions in coronary artery of apolipoprotein $\mathrm{E}$ Knockout mice. Chin J Physiol; 56: 77 - 82.

87. Wick G, Romen M, Amberger A, Metzler B, Mayr M, Falkensammer G, et al. 1997. Atherosclerosis, autoimmunity, and vascular-associated lymphoid tissue. FASEB J, 11:1199-1207.

88. Xu X, Lu H, Lin H, Ni M, Sun H, Li C, et al. 2009. Lymphangiogenesis promotes inflammation and neointimal hyperplasia after adventitial removal in rat carotid artery. Int J Cardiol; 134: 426 427.

89. Yun AJ, Doux JD, Bazar KA, Lee PY, 2005. Adventitial dysfunction: an evolutionary model for understanding atherosclerosis. Medical Hypotheses; 65: 962 - 965.

90. Zhou J, Tang PC, Qin L, Gayed PM, Li W, Skokos EA, et al. 2010. CXCR3 - dependent accumulation and activation of perivascular macrophages is necessary for homestatic arterial remodeling to hemodynamic stresses. J Exp Med; 207: 1951 - 1966. 